\title{
PANORAMA DA LÍNGUA POLONESA FALADA NO INTERIOR DO PARANÁ: DADOS DO VARLINFE
}

\author{
Overview of the Polish Language Spoken in the Countryside of the State of \\ Paraná: Data From Varlinfe
}

\author{
Luciane Trennephol da COSTA \\ Universidade Estadual do Centro-Oeste - UNICENTRO \\ 1tcosta@unicentro.br \\ https://orcid.org/0000-0002-0223-7787
}

\begin{abstract}
RESUMO: No quadro de falta de legitimidade social do plurilinguismo no Brasil, a língua polonesa é uma das línguas faladas em território brasileiro e sobrevive oralmente nas comunidades de descendentes poloneses no interior do estado do Paraná. Neste artigo, com o objetivo de compilar dados acerca da língua polonesa no país, apresentamos alguns fatos históricos acerca do seu uso no Brasil e outros contemporâneos, advindos de amostras do Banco de Dados Variação Linguística de Fala Eslava- VARLINFE. O banco é composto por entrevistas sociolinguísticas com informantes de sete cidades paranaenses e, neste estudo, analisamos dados de três amostras: Cruz Machado, Mallet e Jaciaba. Estes dados e os testemunhos dos informantes são fontes importantes para o registro da situação de bilinguismo, existente em graus variados, e de uso da língua polonesa nas comunidades polonesas do interior paranaense atualmente. PALAVRAS-CHAVE: Plurilinguismo; Língua Polonesa; Bilinguismo; VARLINFE.
\end{abstract}

ABSTRACT: Within the context of lack of legitimacy of plurilingualism in Brazil, Polish is one of the languages spoken in Brazil and survives orally in Polish descendant communities in the countryside of the state of Paraná. This article, aiming at compiling data regarding the Polish language in Brazil, presents some historical facts about its use in the country and other contemporaries coming from samples of VARLINFE (Slavic Speech Variation Database). The database is composed of sociolinguistic interviews with informants from seven cities in Paraná, and, in this study, data from three samples are analyzed: Cruz Machado, Mallet and Jaciaba. Such data and informants' testimonies are important sources for recording the situation of bilingualism, existing in varied degrees, and the use of the Polish language today in Polish communities in the countryside of Paraná. KEY-WORDS: Plurilingualism; Polish language; Bilingualism; VARLINFE. 
A cultura polonesa é parte integrante do patrimônio cultural, material e imaterial, brasileiro. Integra o festejado multiculturalismo brasileiro que não incorpora a legitimidade social das línguas faladas no território de dimensões continentais do país, no qual o ensino formal de línguas adicionais restringe-se praticamente à língua inglesa e por alguns anos escolares. Apesar da falta de fomento às línguas faladas no território brasileiro, elas ainda vicejam e entre elas destaca-se a língua polonesa. Às políticas linguísticas monolíngues no Brasil, acresce-se a carência de informações oficiais acerca do plurilinguismo brasileiro. Neste texto, trazemos alguns dados históricos acerca do uso da língua polonesa no Brasil para, posteriormente, trazermos dados contemporâneos advindos de testemunhos orais de descendentes de imigrantes poloneses no interior do Paraná.

Dados históricos oficiais das línguas estrangeiras faladas no Brasil, incluindo a língua polonesa, são encontrados em registros do Instituto Brasileiro de Geografia e Estatística - IBGE. Em censo demográfico realizado em 1940, figuravam duas perguntas relativas ao uso linguístico: se o recenseado falava correntemente o português e qual língua falava habitualmente no lar. Na publicação, destaca-se o limiar temporal, anterior à Segunda Guerra Mundial, que possibilitou a coleta:

Na época dêsse levantamento, o Brasil mantinha-se ainda neutral no conflito internacional, e a arrogância nazi-fascista se aproximava de seu apogeu, de maneira que as respostas a estas perguntas foram dadas, em geral, com sinceridade completa e, em casos bem numerosos, quase com ostentação, sem qualquer indício das reticências ou dissimulações que sem dúvida se encontrariam se a pesquisa fôsse realizada dois ou três anos mais tarde. (IBGE, 1950, p. 7.)

O número das pessoas que falavam habitualmente no lar uma língua estrangeira, em 1940, era de 1566662 e correspondia a 37,99 por 1000 habitantes. A língua alemã era a mais falada e o polonês figurava como um dos grupos mais numerosos das 196.807 pessoas que falavam outras línguas europeias. Tal publicação apresenta também um cálculo que determina a relação entre o número daqueles imigrantes que continuavam a falar habitualmente a língua e o total dos imigrados presentes no país e também a porcentagem dos falantes na segunda geração de descendentes. No caso da língua polonesa, a persistência na língua de origem era de 47,75 por cem pessoas entre os imigrantes e 42,95 por cem pessoas na segunda geração. No cômputo geral, 77,22\% dos brasileiros natos, ou seja, os descendentes de imigrantes, falavam uma "língua estrangeira ou aborígene". 
Na discriminação por estado, os três estados do Sul lideravam no grupo de pessoas que falavam uma língua estrangeira no lar e no grupo de "outras línguas europeias", que incluía as línguas de povos da Europa Oriental, a língua polonesa figurava como uma das mais importantes. Declararam-se falantes de polonês 22.521 estrangeiros ou brasileiros naturalizados, os imigrantes, e 38.129 brasileiros natos, os seus descendentes. O grupo dos que falavam as línguas polonesa e russa concentravam-se principalmente no Paraná e, em segundo lugar, no Rio Grande do Sul.

De 1940 para cá, não são realizadas pesquisas censitárias institucionais acerca das línguas faladas no Brasil e não temos mais dados numéricos. Nos últimos censos demográficos, aparecem questões acerca do uso linguístico das línguas indígenas. A partir do Censo de 2010, o questionário do IBGE, além de indagar a raça dentre as opções branca, preta, amarela, parda ou indígena, o que já era feito em 2000; indaga também na questão 6.06 "Qual é a sua etnia ou o povo a que pertence" e na questão 6.07 "Fala língua indígena no domicílio?”. Na sequência, a questão 6.08 pede para o informante especificar quais línguas indígenas fala e a 6.09 se fala português no domicílio. Agora em 2020, o IBGE acrescenta a seção 4, intitulada "Identificação Étnico-Racial” e acrescenta os quilombolas.

Dados de publicações escritas demonstram que a língua polonesa não se limitava à modalidade oral. Nas primeiras décadas no Brasil, a partir do início da imigração em fins do século XIX, os imigrantes e seus descendentes mantiveram o uso da língua escrita o que é comprovado pelos inúmeros jornais editados em língua polonesa no Brasil, como o Gazeta Polska w Brazylii e o Lud, pelos quais os poloneses que viviam no país se informavam das notícias da Europa e das colônias existentes no Rio Grande do Sul, Santa Catarina e Paraná (BIELENIN-LENCZOWSKA; STĄPOR, 2017). Embora a maioria dos imigrantes poloneses fossem camponeses de pouca instrução, eles esforçaram-se para propiciar o ensino da língua polonesa escrita aos filhos. Conforme o Calendário Lud de 1948 (WACHOWICZ, 2002), 80\% dos imigrantes eram camponeses. Mesmo assim, preocupavam-se com a vida religiosa e a instrução: "Construída a capela ou a igreja, conforme as possibilidades econômicas das colônias, empreitada esta que se alongava comumente por alguns anos, reuniam-se novamente os colonos, agora para resolverem o problema da alfabetização de seus filhos" (WACHOWICZ, 2002, p. 21). Já em 1876, na fundação da colônia Orleans, no Paraná, foi aberta uma escola polonesa dirigida por Jerônimo Durski, conhecido como o pai das escolas polonesas. Em 1914, existiam 46 escolas polonesas no Paraná, um número que se destaca entre os outros estados do Sul que receberam a imigração polonesa em massa. Pois o Rio Grande do Sul contava com 
17 e Santa Catarina com 9 escolas polonesas. Em meio às dificuldades da oferta de ensino formal no Brasil no início do século XX, o número de escolas polonesas aumentou e em 1937 no Brasil eram 349 e, especificamente no Paraná, eram 167 escolas. Segundo Wachowicz (2002, p. 67), a maioria era do tipo leiga, religiosas eram 30, e também bilíngues. Estas escolas estavam espalhadas pelo interior do Paraná, a cidade de Mallet tinha o mesmo número de escolas que a capital Curitiba, 14 escolas. A cidade de União da Vitória, no interior paranaense, possuía o maior número de escolas polonesas em 1937: 17 escolas.

Esse cenário de educação bilíngue e ensino formal da língua polonesa alterou-se drasticamente com o advento da política de nacionalização do presidente Getúlio Vargas no contexto da Segunda Guerra Mundial. O Decreto-Lei no 406, de 4 de maio de 1938, restringiu a entrada de estrangeiros no país e impôs o ensino em língua portuguesa. A redação do artigo 85 refere-se diretamente à obrigatoriedade do ensino em português nas escolas rurais, contexto da maioria das colônias de imigrantes e seus descendentes na época. O decreto também proibia o ensino de idioma estrangeiro a menores de 14 anos. As publicações impressas em língua estrangeira ficavam sujeitas à autorização do Ministério da Justiça. Novamente as zonas rurais são especificadas no Decreto em seu artigo 86, que estabelece que as publicações impressas nestes espaços estavam sujeitas à permissão do Conselho de Imigração e Colonização. A especificidade apontada no Decreto 406 às zonas rurais demonstra a ciência e preocupação das autoridades brasileiras com a abrangência do uso de outras línguas que não o português no interior do Brasil na época. O contexto político pós guerra e as políticas linguísticas brasileiras refrearam o multilinguismo no país, mas não o aniquilaram. Nas comunidades de imigrantes, principalmente nas mais afastadas dos grandes centros urbanos, a língua dos antepassados manteve-se nas gerações de descendentes.

Esta é a situação no interior do Paraná, na região de abrangência da Universidade Estadual do Centro-Oeste- UNICENTRO, onde vivem muito descendentes de eslavos, ucranianos e poloneses. A cultura eslava faz-se presente materialmente, na arquitetura, na culinária e no artesanato, por exemplo; e também imaterialmente no uso linguístico e nos rituais religiosos e práticas culturais. $\mathrm{O}$ multiculturalismo presente e latente motivou os pesquisadores da universidade a constituírem o Núcleo de Estudos Eslavos - NEES, Programa Permanente de Extensão da UNICENTRO, e a fazerem o mapeamento material e imaterial da cultura polonesa, como também a promoção desta através da oferta de cursos de língua polonesa, de artesanato e de intercâmbio de alunos e professores para a Polônia em convênio com universidades polonesas. O NEES constitui-se de uma equipe 
multidisciplinar com pesquisadores de diversas áreas e é coordenado pela doutora Mariléia Gärtner, professora do Departamento de Letras, campus Irati. No âmbito do NEES, desenvolvem-se pesquisas em áreas variadas e neste texto mencionaremos duas vertentes de pesquisas linguísticas: descrições fonéticas das línguas eslavas faladas no Paraná e pesquisas sociolinguísticas acerca do português brasileiro falado pelos descendentes de eslavos. As descrições de detalhes fonéticos das línguas eslavas, ucraniano e polonês falados no Paraná, por meio de análises acústicas são desenvolvidas no Laboratório de Fonética do NEES. Estas pesquisas descritivas, como a de Costa e Gielinki (2014), acerca do polonês falado em Colônia Duas, interior de Mallet, e de Niewiadomski e Costa (2018) acerca do polonês falado em Rio do Banho, interior de Cruz Machado, demonstram o sistema estrutural, especificamente sonoro, específico da língua polonesa, sem interferências do português, mesmo depois de um século.

Outro eixo de pesquisas linguísticas do NEES são pesquisas sociolinguísticas que buscam descrever o português brasileiro falado pelos descendentes de eslavos. Para tanto, pesquisadores do Núcleo de Estudos Eslavos - NEES constituíram um banco de dados sociolinguísticos com entrevistas de descendentes eslavos com amostras de sete cidades: Cruz Machado, Irati, Ivaí, Mallet, Prudentópolis, Rebouças e Rio Azul. Cada amostra possui no mínimo 24 entrevistas com descendentes de eslavos com 40 minutos de duração cada e realizadas na casa dos entrevistados. Este banco de dados sociolinguísticos destaca-se por ser de regiões consideradas como rurais pelos critérios do IBGE (COSTA; LOREGIAN-PENKAL, 2015) e por ser representativo de descendentes eslavos, poloneses e ucranianos. As entrevistas do VARLINFE, são um importante material de pesquisa acerca da vida atual dos descendentes poloneses e também um testemunho da história deste povo no interior do Paraná. Na metodologia da sociolinguística quantitativa laboviana (LABOV, 2008), procura-se a fala o mais natural possível, o vernáculo, e para deixar o entrevistado bem à vontade, versa-se acerca de questões biográficas e culturais, assuntos que sejam do interesse dos informantes. Assim, ao falar da infância, da vida familiar e comunitária no passado e no presente, as entrevistas do VARLINFE, reúnem importantes testemunhos acerca da cultura e língua polonesa.

Cada munícipio é representado no corpus com, no mínimo, 24 entrevistas sociolinguísticas, correspondentes a 12 informantes femininos e 12 informantes masculinos, divididos em duas faixas etárias, até 50 anos e mais de 50 anos, e três níveis de escolaridade: primário, ginásio e colegial. O primário compreende até quatro anos de estudo e equivale ao atual ensino fundamental 1, o ginásio compreende até oito anos de estudo formal e corresponde ao atual ensino fundamental 2 e o colegial compreende mais 
de oito anos de estudo e equivale ao atual ensino médio. A entrevista, gravada na casa dos informantes, tinha um roteiro de perguntas que versavam sobre assuntos pessoais e de interesse do entrevistado. No entanto, o roteiro é apenas um guia, o importante é o entrevistado falar o mais naturalmente possível. Se durante a entrevista, por exemplo, ele falasse bastante sobre algum assunto que não constava no roteiro, os pesquisadores eram orientados a não o interromper, afinal não nos interessavam as respostas às perguntas feitas e sim a fala vernacular, isto é, o mais natural possível.

Em geral, a receptividade dos descendentes era bem amigável quando da realização das entrevistas, a constituição das amostras deu-se nos anos de 2013 e 2014, e principalmente os mais idosos gostam de falar do passado e dos costumes poloneses. Dois fatos destacaram-se no processo da coleta. O primeiro, é o papel centralizador da mãe, na aquisição da língua, pois geralmente é a língua da mãe, ou polonês ou ucraniano, que o descendente aprende. No caso de etnias híbridas, quando um genitor é de uma etnia, polonesa ou ucraniana, e o outro genitor de outra, a criança aprende a língua da mãe. Delong (2016), discute esse papel da mulher, mãe ou avó, que é a responsável pelo ensino da língua polonesa aos seus filhos ou netos. Conforme a autora, mesmo que a mulher seja de outra etnia é a língua do marido que vai prevalecer em casa haja vista que é uma sociedade machista. Importante destacar que a mulher está sob às ordens do marido assumindo mais um papel, que a autora chama de mulheres fazedoras, que é o de transmitir a língua polonesa aos descendentes.

O segundo fato que se destacou na coleta do VARLINFE, foi o papel da religião na manutenção da língua. Em localidades pequenas e interioranas a vida social gira em torno dos rituais e festas religiosos. Nessas comunidades, ainda hoje ocorrem missas rezadas em polonês e os fiéis rezam e cantam ativamente como também relatado em Delong (2016).

Como era de se esperar, as amostras de diferentes cidades apresentam panoramas culturais heterogêneos e níveis de uso linguístico variados. O grau de bilinguismo (MACKEY, 1968) varia entre as comunidades; em algumas predominam os informantes que falam, e até mesmo adquirem o polonês antes do português, em outras os que apenas entendem e há também uma minoria que também escreve e lê em língua polonesa. Apresentamos neste trabalho, dados das amostras de Cruz Machado, Jaciaba (distrito do município de Prudentópolis) e Mallet, núcleos representativos de cultura polonesa. Importante destacar que, como cada amostra possui apenas 24 informantes no mínimo, a representatividade é pequena. Também que o julgamento de falar a língua polonesa foi subjetivo, baseado na percepção do próprio entrevistado ao declarar-se falante ou 
não da língua polonesa. Nas entrevistas há muita ocorrência de bilinguismo encoberto (WEI, 2000, p. 495): informantes que no primeiro contato dizem apenas entender a língua polonesa e no final da entrevista estão rezando ou cantando em polonês. Importante destacar que alguns entrevistados dizem ler um pouco em polonês também. O que é notável, considerando a baixa escolaridade dos informantes, na média a maioria tem, no máximo, o ensino fundamental completo.

Cruz Machado, núcleo colonial polonês estabelecido em 1911, recebeu em torno de 861 famílias de imigrantes poloneses, aproximadamente 5.500 pessoas conforme Dvorak (2013 apud NIEWIADOMSKI; COSTA, 2019). Em Pátio Velho, lugar no qual se estabeleceram, está o cemitério com os túmulos em pedra dos imigrantes que morreram de tifo no início da colonização e foram enterrados em valas comuns. Os moradores construíram uma nova igreja, mas mantiveram a primeira edificação centenária de madeira (COSTA, 2019). De acordo com o IBGE, no censo demográfico de 2010, o munícipio, distante aproximadamente 300 quilômetros da capital Curitiba, conta com uma população aproximada de 18.040 habitantes, cuja predominância é na zona rural, 66\% da população mora na zona rural.

Em Cruz Machado, de 14 entrevistas com informantes femininas, 12 declararamse falantes de polonês e duas disseram entender a língua. As duas têm etnia híbrida, uma tem etnia polonesa, ucraniana e alemã; e a outra declarou-se ucraniana e polonesa. A maioria das informantes fala polonês com os familiares, pais e irmãos, e amigos; oito falam com os filhos e avós. Os locais em que há o uso da língua polonesa são os ambientes familiares e a igreja, mas quatro informantes afirmaram usar o polonês no trabalho. Quatro informantes disseram ler em polonês e duas também sabem escrever na língua.

Quanto aos doze informantes masculinos da amostra, todos declararam-se falantes de polonês. A maioria também fala polonês com os familiares, pais e irmãos, e amigos; sete falam com os filhos e todos falam com os avós. Os locais nos quais empregam a língua polonesa são os ambientes familiares, igreja e trabalho. Cinco informantes masculinos disseram ler um pouco em polonês e dois sabem escrever na língua.

No relato de uma informante de Cruz Machado, com menos de cinquenta anos, ao ser questionada se preferia falar português ou polonês, percebe-se a língua polonesa como a língua materna, a primeira adquirida, e a afirmação do uso cotidiano do polonês:

"O polonês. Eu prefiro mil vezes fala em polonês. Por que eu acho que é mais fácil para mim fala, é tipo mais leve, sai melhor ...Eu não sei fala em brasileiro quando eu tou em casa." 
Como nosso foco aqui não é a forma linguística, mas a informação das falas dos informantes, trazemos trechos de fala em transcrição ortográfica simples destacados com recuo e itálico. Nos dados de Cruz Machado, destacamos que quase a totalidade da amostra declara-se falante de polonês, mais de cinquenta por cento fala a língua com os filhos, e, além da predominância do uso nos ambientes familiares e na igreja, dez informantes dizem falar o polonês também no local de trabalho. Como a maioria é agricultor, confirma-se o uso majoritário do polonês no cotidiano.

Mallet foi outro importante núcleo de colonização polonesa no interior do estado, a cidade foi iniciada no povoado Rio Claro, que até hoje concentra a comunidade de descendentes poloneses. Como já referido neste texto, em 1937 Mallet tinha o mesmo número de escolas polonesas de Curitiba, 14 escolas. A cidade localiza-se no sudoeste paranaense a 230 quilômetros da capital Curitiba. Em 2019, a população estimada da cidade era de 13.630 pessoas, a maioria moradores da zona rural.

Em Mallet, das 19 entrevistas com informantes femininas, 16 declararam-se falantes da língua polonesa e apenas 3 dizem que entendem a língua, mas não falam. Cinco informantes declararam também falar ucraniano. Em relação aos informantes masculinos em Mallet, temos 13 entrevistas com 10 descendentes, declarando-se falantes de polonês e apenas 3 que dizem não falar a língua eslava e desses três, um entende polonês. Em algumas entrevistas, não só em Mallet, mas também em outras cidades, ainda encontramos descendentes que dizem ter aprendido o português apenas ao entrar na escola. $\mathrm{Na}$ amostra de Mallet, cinco informantes, todas na faixa dos cinquenta anos, dizem ter aprendido o português apenas ao ingressar na escola.

No testemunho de uma informante de Mallet, cujo trecho transcrevemos na próxima citação, com menos de cinquenta anos, atestamos o aprendizado do português apenas na escola e o uso corrente da língua na comunidade:

\footnotetext{
"P: Você aprendeu a falar português na escola?

Na escola.

Isso que aqui a maioria é polonês.

Porque se eles soubessem ler e escrever, que falar é fácil, você vai repetindo e todas as famílias falam polonês, é dificil uma família que não fale, quase todas.

Aham, mas falam entre si, dai. Os mais velhos geralmente.

Não. Todo mundo fala."
}

Jaciaba, que é um distrito do munícipio de Prudentópolis, foi e é uma comunidade típica de poloneses. Longe da sede da cidade e por ela ligada por estrada de terra, é 
uma comunidade relativamente isolada. Nesta comunidade, das 13 entrevistas com informantes masculinos, 7 declaram-se falantes de polonês e 6 dizem que não falam, mas que entendem a língua. Quanto às informantes femininas, das 15 entrevistas, 9 declararamse falantes da língua polonesa e 6 dizem que não falam, mas que entendem a língua. Novamente, os lugares de uso da língua são os ambientes familiares, igreja e trabalho. Nesta amostra, destaca-se o percentual de informantes que dizem apenas entender o polonês, são 15 informantes masculinos e femininos, praticamente a metade. Também oito informantes declaram falar a língua com os filhos como demonstra o testemunho da seguinte informante:

P: E dai o polonês, assim, vocês continuaram falando em casa, daí com outros parentes também?

- Ah se tem algum polonês eu já puxo pra conversar, né. Mas tipo tem muitos.. que já não entende, mas tem algum que entende, já conversamos em polonês. tem que continuar nossa língua...Não abandonar..

Os fios tudo tudo sabem falar... Essa minha nora fala alguma coisa, mas pouco. Essa mais que entende, A Jucélia entende, entende, mas fala não fala. Os dois pais polonês, mas também entende alguma coisa, entende. Mas fala não.

Quando questionada acerca do uso da língua pelos filhos, a mesma informante manifesta sua vontade de que os netos aprendessem a falar polonês, contrastando com a realidade da competência deles na língua ser apenas o entendimento:

\footnotetext{
"Mais óia eu queria que ensinassem dai até os filhos deles pra ... para continuar...

P: Mas eles não sabem os seus netos? Eles entendem?

As meninas entendem ainda, mas começaram a ir para a escola e esqueceram."
}

A partir dos dados e testemunhos apresentados, podemos discutir o status da língua polonesa no interior do Paraná. Ela pode ser considerada uma língua de imigração, uma língua de herança, uma língua brasileira, uma língua minoritária? Entendendo-se língua de imigração como "línguas/variedades originárias de fora do país (por isso, alóctones), que foram trazidas ao Brasil por diferentes grupos de imigrantes, a partir da primeira metade do século XIX..." conforme Raso, Mello e Altenhofen (2011, p. 37), podemos entender que a língua polonesa falada pelos primeiros imigrantes que aqui chegaram, e por isso originária de fora do país, foi uma língua de imigração. Atualmente temos outras línguas de imigração no território brasileiro, por exemplo, as línguas faladas pelos imigrantes 
venezuelanos ou africanos. Mas essa língua/variedade oral falada pelos descendentes de poloneses que são brasileiros, cuja grande maioria nunca foi à Polônia, pode ser considerada ainda uma língua de imigração? Precisamos também considerar a heterogeneidade das comunidades de descendentes poloneses e de suas situações linguísticas. O panorama da língua polonesa falada no interior do Paraná difere do descrito, por exemplo, em Ferreira (2019) na Colônia Dom Pedro II na cidade de Campo Largo, localizada perto da capital Curitiba.

Ferraz (2007, p. 45) define língua minoritária como aquela falada "por um grupo de pessoas num país que tem uma língua oficial diferente, isto é, são línguas naturais, não criadas artificialmente usadas por parcelas da população de um país, e que não se confundem com dialetos da língua oficial.”. A língua polonesa, então, pode ser considerada uma das muitas línguas minoritárias brasileiras, falada nas comunidades de descendentes poloneses e ainda hoje, em algumas dessas comunidades, pode ser a língua materna desses brasileiros e teríamos a situação de línguas maternas que não são uma das duas línguas oficiais do país, o português e a Língua Brasileira de Sinais.

Mas, vimos nos dados aqui apresentados, que nem todos os entrevistados falam o polonês, muitas vezes apenas entendem. Para estes descendentes, a língua polonesa pode ser considerada uma língua de herança no termos de King e Ennser-Kananen (2013) para quem uma língua de herança envolve a língua dos ancestrais, podendo ser indígena, colonial ou de imigração; e pode ou não ser regularmente falada no lar ou na comunidade. É a língua que pode não ser falada, mas faz parte da identidade cultural da comunidade. Em uma grande parte dos descendentes poloneses que não falam a língua, mas tem a polonidade como sua identidade cultural, a língua polonesa é uma língua de herança.

Desta forma, dado os diferentes graus de bilinguismo existentes nas comunidades polonesas do interior paranaense, o status da língua polonesa também varia. Ela pode ser considerada uma língua de imigração no sentido de que foi introduzida no Brasil pelos imigrantes que para cá emigraram no século XIX. É uma língua minoritária falada até hoje nessas comunidades e até mesmo é a língua materna de alguns descendentes nas mais interioranas. Em outras comunidades, é uma língua de herança presente na identidade cultural desses povos.

Os dados aqui apresentados representam uma pequena amostra das comunidades polonesas no interior do Paraná. É necessário conhecer e documentar a situação de uso linguístico dos descendentes de poloneses no Paraná e no Brasil, assim de como de outras línguas faladas no território brasileiro, legitimando o plurilinguismo existente a fim de termos subsídios para mudanças propositivas nas políticas linguísticas brasileiras e apoio 
às discussões do status das línguas aqui faladas. São necessárias pesquisas acerca das línguas eslavas faladas no Brasil que lhes concedam visibilidade, inclusive acadêmica. Citamos aqui o Projeto Enciclopédia das Línguas do Brasil ${ }^{1}$ que cita como línguas europeias no país: alemão, holandês, idich, italiano, leto ou letão e pomerano.

As entrevistas do VARLINFE são um rico material para pesquisas acadêmicas acerca da vida e da história do povo polonês no Brasil. Também comprovam a manutenção da língua oral, aprendida naturalmente em casa e não no ensino formal, e da cultura polonesa ainda fortes depois de mais de um século de imigração. E propiciam pesquisas que contribuem para o conhecimento do multilinguismo brasileiro e para legitimar e socializar a contribuição do povo polonês para a cultura e identidade brasileiras.

1 Disponível no endereço eletrônico: <https://www.labeurb.unicamp.br/elb2/pages/noticias/ noticiasLista.lab?categoria $=4>$. Acesso em 28 de jun. 2020. 


\section{REFERÊNCIAS:}

BIELENIN-LENCZOWSKA, K.; STĄPOR, I. Língua como patrimônio cultural. Práticas linguísticas dos descendentes de poloneses no Sul do Brasil. Revista Del CESLA, n. 20, p. 39-55, 2017.

COSTA, L.T. A voz do silêncio: Registros de línguas eslavas em cemitérios no interior do Paraná. In: VALLE, I. (org.) A produção do conhecimento em Letras, Linguística e Artes. Ponta Grossa: Atena Editora, 2019.

COSTA, L T.; GIELINSKI, M. Detalhes fonéticos do Polonês falado em Mallet. Revista (Con) Textos Linguísticos, v. 8, n. 10, p. 159-174, 2014.

COSTA, L. T.; LOREGIAN-PENKAL, L. A coleta de dados do banco VARLINFE variação linguística de fala eslava: peculiaridades e características. Revista Conexão $U E P G$, v. 11, n. 1, 2015. p. 100-110.

DELONG, S. R. Vitalidade linguística e construção de identidades de descendentes de poloneses no Sul do Paraná. 212f. Tese (Doutorado em Linguística Aplicada) - Programa de Pós-Graduação em Linguística Aplicada, Universidade do Vale do Rio dos Sinos, São Leopoldo, 2016.

FERRAZ, A. P. O panorama linguístico brasileiro: a coexistência de línguas. Revista Filologia e linguística portuguesa, n. 9, p. 43-73, 2007.

FERREIRA, A.M.G. A presença da língua polonesa na Colônia Dom Pedro II, Campo Largo, Paraná. 217f. Dissertação (Mestrado em Letras) - Setor de Ciências Humanas, Universidade Federal do Paraná, Curitiba, 2019.

IBGE. Estudos sobre as línguas estrangeiras e aborígenes faladas no Brasil. Rio de Janeiro: Serviço Gráfico do Instituto Brasileiro de Geografia e Estatística, 1950.

KING, K.; ENNSER-KANANEN, J. Heritage Languages and Language Policy. In: The Encyclopedia of Applied Linguistic. Blackwell Publishing Ltd. Published, 2013

LABOV, W. Padrões sociolinguísticos. São Paulo: Parábola, 2008 [1972].

MACKEY, W. F. The Description of Bilingualism. In: FISCHMAN, J. Readings in the sociology of language. Boston: De Gruyter, 1968.

NIEWIADOMSKI, S.; COSTA, L. Lenição e Epêntese em grupos consonantais tautossilábicos na língua polonesa falada em Cruz Machado, Paraná. Revista Palimpsesto. n. 28, p. 415-439, 2018. 
RASO, T.; MELlO, H.; ALTENHOFEN, C. Os Contatos linguísticos e o Brasil: Dinâmicas pré-históricas, históricas e sociopolíticas. In: MELLO, H.; ALTENHOFEN, C. V.; RASO, T. (Orgs.) Os Contatos Linguísticos no Brasil. Belo Horizonte: Editora UFMG, 2011. p. 1356-216.

WACHOWICZ, R. As escolas da Colonização Polonesa no Brasil. Curitiba: Champagnat, 2002.

WEI, L. The Bilingualism Reader. New York: Routledge, 2000. 